Int. J. Electrochem. Sci., 14 (2019) $11491-11508$

\title{
Corrosion Protection of Mild Steel by the Synergetic effect of Sodium Dodecylbenzenesulfonates and Zinc Sulfate in Sodium Chloride Solution
}

\author{
I.Ismail ${ }^{1, *}$, M.K. Harun ${ }^{1}$, M.Z.A. Yahya ${ }^{2}$ \\ ${ }^{1}$ Electrochemical and Corrosion Science Laboratory, Faculty of Applied Science, Universiti Teknologi \\ MARA, 40450 Shah Alam Selangor, Malaysia \\ ${ }^{2}$ Faculty of Defence Science \& Technology, Universiti Pertahanan Nasional Malaysia, 57000 Kuala \\ Lumpur, Malaysia \\ *E-mail: ismaliza@lgm.gov.my
}

doi: $10.20964 / 2019.12 .20$

Received: 31 June 2019 / Accepted: 14 September 2019 / Published: 29 October 2019

The corrosion inhibition of sodium dodecylbenzenesulfonates surfactant (SDBS) and SDBS incorporated with various concentrations of zinc sulfate $\left(\mathrm{ZnSO}_{4}\right)$ on mild steel, in $0.05 \mathrm{M} \mathrm{NaCl}$ at $25{ }^{\circ} \mathrm{C}$ were investigated using the electrochemical impedance spectroscopy (EIS) and polarization measurements. The adsorption behavior of SDBS was investigated through different adsorption isotherms. Characterization of the organic film on mild steel surface was done through the Fourier transform infrared spectroscopy (FTIR) analysis. The EIS results found that the corrosion inhibition efficiency (IE) of SDBS was enhanced in the presence of $\mathrm{ZnSO}_{4}$, showing the maximum value of $96 \%$ at mixtures of 200:200 ppm SDBS: $\mathrm{ZnSO}_{4}$. The polarization measurement found that the IE for a similar sample was $95 \%$, which agrees well with the EIS results. The calculated thermodynamic parameter reveals that the adsorption process of SDBS obeys the Langmuir adsorption isotherm with the correlation coefficient, $\mathrm{R}^{2}$ of 0.996 . The calculated free energy of adsorption was $-33 \mathrm{kJmol}-1$ which indicated strong adsorption of SDBS on mild steel surface both through physisorption and chemisorption. The FTIR analysis confirmed the presence of the adsorbed organic film on the mild steel surface.

Keywords: Corrosion, mild steel, inhibitor, surfactant, adsorption

\section{$\underline{\text { FULL TEXT }}$}

(C) 2019 The Authors. Published by ESG (www.electrochemsci.org). This article is an open access article distributed under the terms and conditions of the Creative Commons Attribution license (http://creativecommons.org/licenses/by/4.0/). 